\title{
Patient choice as a driver of medication-switching in non-adherent individuals with bipolar disorder
}

\author{
This article was published in the following Dove Press journal: \\ Patient Preference and Adherence \\ 17 April 2014 \\ Number of times this article has been viewed
}

\author{
Martha Sajatovic ${ }^{1,2}$ \\ Curtis Tatsuoka ${ }^{2}$ \\ Philipp Dines \\ Christopher S Bialko' \\ Melanie Athey' \\ Tiffany Williams' \\ Kristin A Cassidy' \\ 'Department of Psychiatry, \\ 2Department of Neurology, Case \\ Western Reserve University School \\ of Medicine, University Hospitals \\ Case Medical Center, Cleveland, \\ $\mathrm{OH}$, USA
}

Objective: Psychotropic-related weight gain is a common concern among patients with bipolar disorder (BD). This concern affects satisfaction with treatment and may lead to non-adherence and relapse. This was a 12-week, uncontrolled prospective trial of patient-choice-facilitated ziprasidone switching among non-adherent BD patients with weight concerns. This study was conducted from January 2011 to July 2012.

Method: Patients were asked to identify the "offending" BD medication which they believed was causing weight problems, and this agent was replaced with ziprasidone. The primary outcome was change in adherence as measured with the Tablets Routine Questionnaire (TRQ). Secondary outcomes included medication attitudes, BD symptoms, global psychopathology, social functioning, and quality of life.

Results: The most common agents causing weight concerns were quetiapine ( $\mathrm{N}=7,23 \%)$, aripiprazole ( $\mathrm{N}=4,13 \%)$, olanzapine, lithium, and divalproex (all $\mathrm{N}=3,10 \%)$. Adherence improved from a baseline of missing $48.6 \%$ of prescribed BD medication in the past week (44.9\% in the past month) to missing $25.3 \%(P=0.002)$ of prescribed BD medication in the past week $(P<0.001$, in the past month) at endpoint. Medication attitudes, symptoms, functioning, and quality of life improved but there were no differences in body weight.

Conclusion: While findings must be tempered by methodological limitations such as small sample and uncontrolled design, patient-facilitated medication-switching appeared to improve adherence and BD outcomes in these non-adherent individuals. Additional studies involving patient-facilitated medication-switching and shared decision-making in $\mathrm{BD}$ are needed.

Keywords: bipolar disorder, ziprasidone, antipsychotic, adherence, weight gain, shared decision-making

\section{Introduction}

Medication-related weight gain is common among patients with bipolar disorder (BD). This affects treatment satisfaction and may lead to reduced adherence. Patient-centered care, as defined by the Institute of Medicine (IOM), is "care that is respectful of and responsive to individual patient preferences, needs, and values". ${ }^{1}$ Ideally, care that is both patient-centered and evidence-based can lead to active patient engagement and good outcomes.

Ziprasidone is a second-generation antipsychotic medication ${ }^{2}$ approved by the US Food and Drug Administration (FDA) for acute treatment of BD manic and mixed episodes and for BD maintenance as an adjunct treatment. Ziprasidone may have a minimal potential for weight gain and dyslipidemia. ${ }^{3-5}$
Correspondence: Martha Sajatovic Department of Psychiatry, University Hospitals Case Medical Center, III 00 Euclid Avenue, Cleveland, $\mathrm{OH}$, USA

$\mathrm{Tel}+\mathrm{I} 2168442808$

Fax +l 2168442742

Email martha.sajatovic@uhhospitals.org 
This was a 12-week, uncontrolled prospective trial of patient-facilitated medication-switching among poorly adherent BD patients who self-identified medication-related weight concerns as their reason for non-adherence. Patients were asked to self-select the BD medication which they believed was causing weight problems. We anticipated that patient-choice-driven switching would lead to improved adherence. We also evaluated effects of patient-choice-driven switching on medication attitudes and clinical outcomes.

\section{Methods}

\section{Setting and population}

We enrolled individuals $\geq 18$ years of age with type I or II BD confirmed with the Mini International Neuropsychiatric Inventory (MINI). ${ }^{6}$ The study was approved by the institutional review board, all participants provided informed consent, and oversight included an external Data and Safety Monitoring Board (DSMB).

All individuals were on maintenance BD medication (lithium, antipsychotic, anticonvulsant), had medication weight gain concerns, and poor adherence defined as missing $\geq 20 \%$ of prescribed BD medications as measured by the Tablet Routines Questionnaire (TRQ), ${ }^{7,8}$ which was related to weight concerns. Individuals were excluded if they had a contraindication to ziprasidone, eating disorder, substance dependence, clozapine treatment, financial reasons for non-adherence, medical conditions that could interfere with protocol participation, or were at risk of harm to themselves or others. Pregnant and breastfeeding women were excluded. The study was conducted from January 2011 to July 2012.

\section{Study assessments}

Participants completed assessments at baseline and at 2-, 4-, 8-, and 12-week follow-up. Treatment satisfaction was assessed at study endpoint, and post-study at 16 weeks.

\section{Primary outcome}

Adherence behavior was assessed with the Tablets Routine Questionnaire (TRQ). ${ }^{7,8}$

\section{Secondary outcomes}

Secondary measures included the Morisky Rating Scale, ${ }^{9}$ an additional brief self-reported adherence assessment, and adherence attitudes measured with the Drug Attitude Inventory (DAI) scale. ${ }^{10}$ Depressive symptoms were measured with the Montgomery-Åsberg Depression Rating Scale (MADRS) ${ }^{11}$ and manic symptoms were measured with the Young Mania Rating Scale (YMRS). ${ }^{12}$ Global psychopathology was measured with the Clinical Global Impressions (CGI) scale. ${ }^{13}$ Functioning was measured with the Social and Occupational Functioning Scale (SOFAS), ${ }^{14}$ and the Global Assessment of Functioning (GAF) scale. ${ }^{15}$ Quality of life was measured with the 12-item Short Form Health Survey (SF-12). ${ }^{16}$

Biological and safety outcomes included body mass index (BMI), vital signs, laboratory testing (electrolytes, renal, thyroid and liver functions, total cholesterol, triglycerides, complete blood count), and electrocardiography. Involuntary movements were evaluated with the Abnormal Involuntary Movement Scale (AIMS), ${ }^{17}$ Simpson-Angus Scale (SAS), ${ }^{18}$ and Barnes Akathisia Scale (BARS). ${ }^{19}$ Reported side effects were assessed at every study visit.

\section{Intervention}

\section{Ziprasidone}

During screening, the study research psychiatrist evaluated the feasibility of switching from the maintenance BD medication that the individual identified as causing weightrelated non-adherence. Only a single drug was permitted to be identified as the "offending" agent. If an individual was not able to identify which medication caused the most weight gain concerns, the most recently initiated medication was selected. Ziprasidone was titrated up to a maximum of $160 \mathrm{mg}$ /day with dose reductions as clinically indicated. Offending agents were discontinued.

\section{Concomitant treatments}

Stable psychotropic drugs prescribed prior to baseline (except for the patient-identified offending agent) were continued. New psychotropic medications were prohibited.

\section{Data analysis}

Descriptive statistics were calculated for baseline characteristics. We conducted a modified intent-to-treat analysis for subjects who received at least one dose of study medication. Separate longitudinal mixed models were fit with first-order autoregressive, AR (1) covariance matrix, for the primary adherence and for the symptom measures with TRQ weekly and monthly, with YMRS, and with MADRS as the dependent variable.

\section{Results}

\section{Screened and enrolled samples}

Fifty-five individuals were screened, 32 fit eligibility criteria and consented, and 30 were eventually enrolled. Age, sex, and race did not differ significantly between screened and enrolled patients. One consented individual did not complete baseline 
assessments and another had elevated liver function tests that were a contraindication to ziprasidone. Table 1 illustrates baseline demographic and clinical variables.

\section{Ziprasidone treatment}

The mean endpoint dose of ziprasidone was $61.3 \mathrm{mg} /$ day (standard deviation [SD]: 31.9, range: $20-120 \mathrm{mg} /$ day).

\section{BD agents identified by patients as causing weight gain concerns}

Table 1 illustrates BD agents replaced in patient-choicedriven switching. The most common weight concern agents were quetiapine $(\mathrm{N}=7,23 \%)$, aripiprazole $(\mathrm{N}=4,13 \%)$, and olanzapine, lithium, and divalproex (all $\mathrm{N}=3,10 \%$ ). Nearly all (29/30) individuals readily identified the medication they perceived as most problematic for weight gain.

\section{Concomitant medication}

In addition to ziprasidone, individuals were on other BD treatments including antidepressants $(22 / 30,73 \%)$, anticonvulsants $(10 / 30,33 \%)$, lithium $(2 / 30,7 \%)$, stimulants $(1 / 30$, $3 \%$ ), and one individual on long-acting injectable risperidone (3\%). Including ziprasidone, there was a mean of $2.2 \mathrm{BD}$ medications (SD: 0.889 , mode: 2 , range: $1-4)$. Seven individuals $(23 \%)$ received ziprasidone monotherapy.

Table I Characteristics of 30 non-adherent individuals with BD who received patient-choice-driven medication-switching

\begin{tabular}{ll}
\hline Variable & Value \\
\hline Mean age in years (SD, range) & $44.2(10.2,23-69)$ \\
Female N (\%) & $15(50)$ \\
Race N (\%) & $13(43)$ \\
$\quad$ White & $16(53)$ \\
Black & $1(3)$ \\
Other & $4(13)$ \\
Hispanic ethnicity N (\%) & $11.7(2.6,6-18)$ \\
Mean education in years (SD, range) & \\
Marital status N (\%) & $14(47)$ \\
Single, never married & \\
Type of bipolarity N (\%) & $28(93)$ \\
Type I & $2(7)$ \\
Type II & $23.9(12.1,10-65,20)$ \\
Mean age at onset of illness in years & \\
(SD, range, median) & $22(73)$ \\
Past suicide attempt N (\%) & \\
Offending BD agent N (\%) & $3(10)$ \\
Lithium & $4(13)$ \\
Anticonvulsant & $18(60)$ \\
Antipsychotic & $5(17)$ \\
Antidepressant &
\end{tabular}

Abbreviations: BD, bipolar disorder; SD, standard deviation.

\section{Drop-outs}

Six subjects $(20 \%)$ terminated the study prematurely. Four $(13 \%)$ were lost to follow up, one (3\%) dropped out due to hospitalization, and one ( $3 \%$ ) due to ziprasidone side effects (gastrointestinal [GI] distress).

\section{Primary outcome}

Table 2 includes univariate analysis of TRQ change. Adherence improved from missing $48.6 \%$ of medication in the past week to missing $25.3 \%$. Table $3 \mathrm{~A}$ and B illustrate estimated TRQ weekly and monthly means with respect to time period using longitudinal mixed models. Time periods and sex were viewed as factor levels, and age was included as a covariate. Subject-level random intercepts were fitted as well. Time period factor $P$-values for both TRQ weekly and monthly were $<0.001$, indicating that TRQ was significantly changed while sex and age were not significant.

Table 2 Change from baseline in adherence, treatment attitudes, BD symptoms, functioning, and biological parameters among individuals in patient-choice-driven medication-switching

\begin{tabular}{|c|c|c|c|}
\hline Variable & Baseline* & 12 weeks* & $\begin{array}{l}\text { Statistic: } t, d f \text {, } \\
P \text {-value }\end{array}$ \\
\hline \multicolumn{4}{|l|}{ TRQ } \\
\hline Past week & $48.6(20.1)$ & $25.3(26.9)$ & $-3.425,23,0.002$ \\
\hline Past month & $44.9(19.1)$ & $19.4(18.4)$ & $-5.226,23,<0.001$ \\
\hline Morisky & $2.4(0.9)$ & $0.8(1.0)$ & $-6.652,22,<0.001$ \\
\hline \multicolumn{4}{|l|}{ scale } \\
\hline $\mathrm{Al}$ & $7.2(2.1)$ & $8.6(1.4)$ & $3.058,23,0.006$ \\
\hline GI & $4.1(0.9)$ & $2.5(I . I)$ & $-5.619,23,<0.001$ \\
\hline 1ADRS & $19.5(11.4)$ & $8.5(7.0)$ & $-5.042,23,<0.001$ \\
\hline YMRS & $9.5(6.5)$ & $4.4(4.6)$ & $-3.426,23,0.002$ \\
\hline AIMS & I.3 (2.4) & $1.8(3.1)$ & $0.406,22,0.688$ \\
\hline SAS & $0.4(0.7)$ & $0.2(0.4)$ & $-1.283,22,0.213$ \\
\hline BAS & $0.03(0.19)$ & $0.13(0.45)$ & $1.367,22,0.186$ \\
\hline \multicolumn{4}{|l|}{ SF-12 } \\
\hline Mental score & $37.1(9.6)$ & $45.2(10.3)$ & $3.550,22,0.002$ \\
\hline Physical score & $39.8(14.5)$ & $42.9(12.5)$ & $1.178,22,0.252$ \\
\hline SOFAS & $51.0(8.9)$ & $57.4(12.2)$ & $2.710,23,0.012$ \\
\hline \multicolumn{4}{|l|}{ Physical } \\
\hline \multicolumn{4}{|l|}{ parameters } \\
\hline BMI & $33.6(8.9)$ & $34.0(9.1)$ & $-0.988,23,0.334$ \\
\hline \multicolumn{4}{|l|}{ cholesterol (mg/dL) } \\
\hline Triglycerides (mg/dL) & |37.| (90.3) & I39.0 (7I.I) & $-0.388,22,0.702$ \\
\hline \multicolumn{4}{|l|}{ on EKG (ms) } \\
\hline \multicolumn{4}{|c|}{$\begin{array}{l}\text { Note: *All values reported as mean (SD) using univariate analysis. } \\
\text { Abbreviations: AIMS, Abnormal Involuntary Movement Scale; BAS, Barnes } \\
\text { Akathisia Scale; BD, bipolar disorder; BMI, Body Mass Index; CGI, Clinical Global } \\
\text { Impression; DAI, Drug Attitudes Inventory; EKG, electrocardiography; MADRS, } \\
\text { Montgomery Asberg Rating Scale; SAS, Simpson Angus Scale; SD, standard deviation; } \\
\text { SF-I2, Medical Outcomes Study Short Form General Health Survey; SOFAS, Social } \\
\text { and Occupational Functioning Scale; TRQ, Tablet Routines Questionnaire; YMRS, } \\
\text { Young Mania Rating Scale; QTc, corrected QT interval; df, degrees of freedom. }\end{array}$} \\
\hline
\end{tabular}


Table 3 Estimated means of TRQ in the past week/past month with respect to time period

\begin{tabular}{|c|c|c|c|c|c|c|c|c|c|c|}
\hline \multirow[t]{3}{*}{ Time period } & \multicolumn{5}{|c|}{ Past week } & \multicolumn{5}{|c|}{ Past month } \\
\hline & \multirow[t]{2}{*}{ Mean } & \multirow[t]{2}{*}{ SE } & \multirow[t]{2}{*}{$d f$} & \multicolumn{2}{|c|}{$95 \%$ confidence interval } & \multirow[t]{2}{*}{ Mean } & \multirow[t]{2}{*}{ SE } & \multirow[t]{2}{*}{$d f$} & \multicolumn{2}{|c|}{ 95\% confidence interval } \\
\hline & & & & Lower bound & Upper bound & & & & Lower bound & Upper bound \\
\hline \multicolumn{11}{|c|}{ TRQ estimates $^{\mathbf{a}}$} \\
\hline Base & $43.74^{b}$ & 4.28 & 66.46 & 35.19 & 52.29 & $43.05^{c}$ & 4.13 & 55.4 & 34.78 & 51.32 \\
\hline Week I & $44.63^{b}$ & 4.34 & 69.18 & 35.98 & 53.28 & $42.28^{c}$ & 4.17 & 57.3 & 33.93 & 50.63 \\
\hline Week 2 & $14.23^{\mathrm{b}}$ & 4.35 & 69.13 & 5.56 & 22.91 & $22.48^{c}$ & 4.73 & 79.69 & 13.07 & 31.89 \\
\hline Week 4 & $11.48^{b}$ & 4.65 & 81.96 & 2.23 & 20.72 & $9.24^{c}$ & 4.46 & 67.93 & 0.35 & 18.13 \\
\hline Week 8 & $21.90^{\mathrm{b}}$ & 5.12 & 101.92 & 11.76 & 32.05 & $14.84^{c}$ & 4.82 & 83.07 & 5.24 & 24.43 \\
\hline Week 12 & $26.84^{b}$ & $4.4 I$ & 71.68 & 18.06 & 35.62 & $20.59^{c}$ & 4.23 & 59.42 & 12.13 & 29.05 \\
\hline Week I6 & $20.0 \mathrm{I}^{\mathrm{b}}$ & 5.1 & 93.78 & 9.88 & 30.14 & $16.24^{c}$ & 4.81 & 79.93 & 6.68 & 25.81 \\
\hline
\end{tabular}

Notes: ${ }^{a}$ Computed average: proportion of doses missed over the time period; ${ }^{b}$ covariates appearing in the model are evaluated at the following values: age $=45.7 \mathrm{I}$ years; 'covariates appearing in the model are evaluated at the following values: age $=45.73$ years.

Abbreviations: SE, standard error; TRQ, Tablet Routines Questionnaire; $d f$, degrees of freedom.

\section{Secondary outcomes}

Table 2 illustrates univariate analyses that show improvement in symptoms, attitudes, global psychopathology, mental component of the SF-12, and functioning. The physical component of the SF-12 was unchanged. Both depressive and manic symptoms improved. Time periods and sex were viewed as factor levels, and age was included as a covariate. Subject-level random intercepts were fit as well. Time period factor was significant for YMRS $(P=0.010)$ and MADRS $(P<0.001)$, while sex and age were not significant.

\section{Tolerability and adverse effects}

As noted in Table 2, there were no changes in physical parameters, including BMI. Side effects that occurred in more than $5 \%$ of patients were sedation ( $\mathrm{N}=20,67 \%)$, GI disturbance $(\mathrm{N}=11,37 \%)$, mild-to-moderate muscle twitching or contraction $(\mathrm{N}=6,20 \%)$, restless/akathisia $(\mathrm{N}=3,10 \%)$, and sexual dysfunction $(\mathrm{N}=2,7 \%)$. There were six serious adverse events (SAEs), none of which were deemed by the DSMB to be study related. Four of the SAEs were hospitalizations due to suicidal thinking or suicide attempts in which ziprasidone was continued in three cases and stopped in one case. One SAE was a non-related car accident and one SAE was an emergency room visit for acute bronchitis.

\section{Patient satisfaction and post-study continuation on ziprasidone}

Treatment satisfaction information was available for 26 individuals. Of these, 24 (92\%) strongly agreed or agreed that they were satisfied with ziprasidone, and $22(81 \%)$ strongly agreed or agreed that they had less weight concerns compared to the previous offending agent. Twenty-three individuals (89\%) agreed or strongly agreed that the benefits of ziprasidone outweighed the side effects. Among
17 individuals for whom post-study status was available, 16 individuals (94\%) were still on ziprasidone.

\section{Discussion}

This open-label, uncontrolled trial of patient-driven medication-switching suggested that BD patients with poor adherence and medication-related weight gain concerns had improvements in adherence, medication attitudes, symptoms, and functioning. In spite of less weight concern, there were no differences in body weight.

More than half of people with BD are poorly adherent and poor adherence is related to negative outcomes. ${ }^{20}$ Patient-driven medication-switching may help in engaging individuals to a greater extent in their own care. This is consistent with the importance of shared decision-making in psychiatric practice. ${ }^{21}$ In this study we allowed patients to make the choice as to which of their medications should be replaced. Atypical antipsychotics, lithium, and antidepressants were all sources of weight concerns. Patients welcomed the opportunity to provide input on pharmacotherapy decision-making and valued the consideration of relative burdens and benefits of their therapeutic regimen. Perhaps adherence and attitude improvement were related to individuals feeling that they had an active involvement in treatment. Symptom and functional status improvement may have been due to better adherence. Most individuals were satisfied with patient-facilitated drug-switching.

In contrast to our initial expectation, we did not find a change in BMI. It is possible that because patients were poorly adherent to begin with, any weight change related to formally discontinuing a drug causing weight gain was obscured. Alternatively, since BMI is a difficult factor to change in people with serious mental illness, ${ }^{22}$ and our study did not include a diet or exercise component, it is perhaps not surprising that BMI was unchanged. 
In conclusion, actively involving $\mathrm{BD}$ patients with medication-related weight concerns in prescribing decisions improved adherence and weight concerns, but did not change actual body weight. The interpretation of the study findings must be tempered with the methodological limitations, including small sample and the uncontrolled openlabel design. Additional studies involving patient-driven medication-switching in BD are needed.

\section{Disclosure}

Dr Sajatovic has been the recipient of research grants from Pfizer, Merck, and Ortho-McNeil Janssen and is a consultant to Bracket/United BioSource, Prophase, Otsuka, Pfizer, and Amgen. Dr Curtis Tatsuoka receives financial support from Pfizer.

This study was supported by an investigator-initiated research grant from Pfizer, USA (New York, NY, USA; all authors; grant \#WS883414).

The study has been registered on ClinicalTrials.gov with ID Number: NCT01293825. Portions of this data have been presented at the 9th International Conference on Bipolar Disorder; Pittsburgh, PA, USA; June 10, 2011, and 10th International Conference on Bipolar Disorder; Miami, FL, USA; June 15, 2013.

The authors report no other conflicts of interest in this work.

\section{References}

1. National Research Council. Crossing The Quality Chasm: A New Health System for the 21st Century. Washington, DC: National Academies Press; 2001.

2. Seeger TF, Seymour PA, Schmidt AW, et al. Ziprasidone (CP-88,059): a new antipsychotic with combined dopamine and serotonin receptor antagonist activity. J Pharmacol Exp Ther. 1995;275(1):101-113.

3. Bowden CL, Vieta E, Ice KS, Schwartz JH, Wang PP, Versavel M. Ziprasidone plus a mood stabilizer in subjects with bipolar I disorder: A 6-month, randomized placebo-controlled, double-blind trial. J Clin Psychiatry. 2010;71(2):130-137.

4. Warrington L, Lombardo I, Loebel A, Ice K. Ziprasidone for the treatment of acute manic or mixed episodes associated with bipolar disorder. CNS Drugs. 2007;21(10):835-849.
5. Weiden PJ, Newcomer JW, Loebel AD, Yang R, Lebovitz HE Long-term changes in weight and plasma lipids during maintenance treatment with ziprasidone. Neuropsychopharmacology. 2008;33(5): 985-994.

6. Sheehan DV, Lecrubier Y, Sheehan KH, et al. The Mini-International Neuropsychiatric Interview (M.I.N.I.): the development and validation of a structured diagnostic psychiatric interview for DSM-IV and ICD-10. J Clin Psychiatry. 1998;59 Suppl 20:22-33;quiz 34-57.

7. Peet M, Harvey NS. Lithium maintenance: 1. A standard education programme for patients. Br J Psychiatry. 1991;158:197-200.

8. Scott J, Pope M. Nonadherence with mood stabilizers: prevalence and predictors. J Clin Psychiatry. 2002;63(5):384-390.

9. Morisky DE, Green LW, Levine DM. Concurrent and predictive validity of a self-reported measure of medication adherence. Med Care. 1986;24(1):67-74.

10. Awad AG. Subjective response to neuroleptics in schizophrenia. Schizophr Bull. 1993;19:609-618.

11. Montgomery S, Asberg M. A new depression scale designed to be sensitive to change. Br J Psychiatry. 1979;134:382-389.

12. Young RC, Briggs JT, Ziegler VE. A rating scale for mania: reliability, validity, and sensitivity. Br J Psychiatry. 1978;133:429-435.

13. Guy W. Clinical Global Impressions. ECDEU Assessment Manual for Psychopharmacology. Publication No (ADM). Rockville, MD: US Department of Health, Education, and Welfare, DHEW; 1976: 76-338.

14. Morosini PL, Magliano L, Brambilla L, Ugolini S, Pioli R. Development, reliability and acceptability of a new version of the DSM-IV Social and Occupational Functioning Assessment Scale (SOFAS) to assess routine social functioning. Acta Psychiatr Scand. 2000;101(4):323-329.

15. Jones SH, Thronicroft G, Coffey M, Dunn G. A brief mental health outcome scale-reliability and validity of the Global Assessment of Functioning (GAF). Br J Psychiatry. 1995;166(5):654-659.

16. Ware J Jr, Kosinski M, Keller SD. A 12-Item Short-Form Health Survey: construction of scales and preliminary tests of reliability and validity. Med Care. 1996;34(3):220-233.

17. Guy W. Abnormal Involuntary Movement Scale. ECDEU Assessment Manual for Psychopharmacology. Publication No (ADM). Rockville, MD: US Department of Health, Education, and Welfare, DHEW; 1976: 76-338.

18. Simpson GM, Angus JWS. A rating scale for extrapyramidal side effects. Acta Psychiatr Scand Suppl. 1970;212:11-19.

19. Barnes TRE. A rating scale for drug-induced akathisia. Br J Psychiatry. 1989;154:672-676.

20. Lage MJ, Hassan MK. The relationship between antipsychotic medication adherence and patient outcomes among individuals diagnosed with bipolar disorder: a retrospective study. Ann Gen Psychiatry. 2009;8:7.

21. Patel SR, Bakken S, Ruland C. Recent advances in shared decision making for mental health. Curr Opin Psychiatry. 2008;21(6):606-612.

22. Daumit GL, Dalcin AT, Jerome GJ, et al. A behavioral weight loss intervention for persons with serious mental illness in psychiatric rehabilitation centers. Int J Obes (Lond). 2011;35(8):1114-1123.
Patient Preference and Adherence

\section{Publish your work in this journal}

Patient Preference and Adherence is an international, peer-reviewed, open access journal focusing on the growing importance of patient preference and adherence throughout the therapeutic continuum. Patient satisfaction, acceptability, quality of life, compliance, persistence and their role in developing new therapeutic modalities and compounds to

\section{Dovepress}

optimize clinical outcomes for existing disease states are major areas of interest. This journal has been accepted for indexing on PubMed Central. The manuscript management system is completely online and includes a very quick and fair peer-review system. Visit http://www.dovepress.com/ testimonials.php to read real quotes from published authors. 